\section{Bibliometric characteristics of predatory journals in pediatrics}

Advance online publication, 30 May 2018; doi:10.1038/pr.2018.54

To the Editor: In the past decade, scientific publishing was characterized with the open-access model, unfortunately with the side effect of the appearance of the so-called predatory journals. These predatory journals caused a serious problem to the integrity of medical research, due to rising retraction rates, irreproducible results, and a flood of low quality publications(1). Features of predatory journals are an extremely quick, non existing or unclear peer-review process (sometimes less than one week), false credibility of the editorial board, less than five members of the editorial board, lack of or falsification of institutional affiliations, homepages containing spelling errors, bogus impact factors, e-mail spam, small number of published papers and smaller publication and processing fees(2). To help researchers identify predatory journals, some webpages maintain the lists of possible predatory journals $(3,4)$. The field of pediatrics is also a victim of this latest trend. While the archived Beale list(3) contains just two, the BHI Predatory Journal list(4) includes 26 suspicious pediatric journals. Interestingly, the two journals from the Beale list are not included in the BHI list; however, all the journals in the BHI list are published by suspicious publishers contained in the Beale list. None of the suspicious journals are indexed in Medline, but two of them are indexed in Scopus.

Most of those journals could be relatively easy to identify using the features enumerated above. Nevertheless, we were interested how less obviously identifiable predatory journals could be distinguished from their non-suspicious counterpart. In that manner we compared two journals included in Beale and BHI lists indexed in Scopus (PJ1 and PJ2) with a pediatric journal (JComp) having a comparable SJR (Scopus Journal
Rank), a randomly selected pediatric journal with an average SJR (JAvg) and the first ranked Journal in the Pediatrics, Perinatology and Child Health subject area in Scopus (JFirst) using bibliometric indicators. We analyzed papers published during the period 2013-2017. The search was done on $18^{\text {th }}$ November 2017. We compared the number of published papers, type of papers, the production of ten most prolific countries and five most prolific institutions, the number of countries needed to produce $80 \%$ of papers, number of countries and authors, and the size of county co-author networks.

The results of the comparison are presented in Table 1. We see that the JFirst and JAvg differs quite clearly from PJ1 and PJ2 in terms of bibliometrics indicators. On the contrary, the JComp falls in somewhere between two above groups, and could belong to each one. Thereafter, we may claim that the main, not yet reported differences between non-suspicious journals (NSJs) and possible predatory journals (PPJs) are:

- Number of types of papers published. PPJs don't publish editorials, erratum, and articles in press;

- The distribution of papers in NSJs is spread to substantially more authors and countries than in PPJs

- The most prolific NSJs authors and institutions produce much smaller share of total number of papers than most prolific PPJs authors and institutions

- A considerable number of countries are involved in coauthor networks in NSJs than in PPJs.

To conclude, the easiest, but not the most accurate way to distinguishes between non-suspicious and possible predatory journals is to inspect if the journal in question is listed in predatory journal's list. Another possibility is to try if the journal is indexed in Scopus, Web of Science, or Medline, but as noted above indexing is not yet the guarantee that the journal is not predatory. Analyzing the simple bibliometric characteristics of the journal in question is the third possibility. Significant number of papers from same authors and institutions, absence of editorials, erratum, and article in press is a clear sign that the journal is probably predatory. 


\section{Letter to the Editor}

Table 1. The comparison of bibliometrics attributes of journals

\begin{tabular}{|c|c|c|c|c|c|c|c|c|}
\hline & $\begin{array}{c}\text { Number of } \\
\text { papers }\end{array}$ & $\begin{array}{l}\text { Number of } \\
\text { paper types }\end{array}$ & $\begin{array}{l}\text { Top ten authors } \\
\text { productivity }\end{array}$ & $\begin{array}{c}\text { Top five } \\
\text { institutions } \\
\text { productivity }\end{array}$ & $\begin{array}{c}\text { Number of } \\
\text { countries } \\
\text { producing } 80 \% \\
\text { of papers }\end{array}$ & $\begin{array}{l}\text { Number of } \\
\text { authors }\end{array}$ & $\begin{array}{l}\text { Number of } \\
\text { countries in } \\
\text { co-authors } \\
\text { networks }\end{array}$ & $\begin{array}{l}\text { Number of } \\
\text { countries }\end{array}$ \\
\hline JFirst & 1569 & 7 & 5,5 & 32,56851 & 2 & 6325 & 81 & 91 \\
\hline JAvg & 1312 & 8 & 3,1 & 12,95732 & 3 & 5125 & 32 & 79 \\
\hline JComp & 529 & 7 & 13,8 & 38,56333 & 1 & 1389 & 5 & 37 \\
\hline PJ1 & 649 & 3 & 14,6 & 70,41602 & 1 & 1737 & 10 & 31 \\
\hline PJ2 & 426 & 4 & 16,0 & 40,84507 & 5 & 606 & 3 & 57 \\
\hline
\end{tabular}

Disclosure: The authors declare no competing interests.

\section{Peter Kokol ${ }^{1}$, Jernej Završnik ${ }^{2}$, Bojan Žlahtič ${ }^{1}$ and Helena Blažun Vošner ${ }^{3}$}

${ }^{1}$ University of Maribor, Faculty of Electrical Engineering and Computer Science, Smetanova ulica 17, 2000 Maribor,

Slovenia;

${ }^{2}$ Dr. Adolf Drolc Healthcare Centre, Ulica talcev 9, 2000

Maribor, Slovenia; ${ }^{3}$ University of Maribor, Faculty of Health

Sciences, Center for International Cooperation, Žitna ulica 15, 2000 Maribor, Slovenia.
Correspondence: Peter Kokol (peter.kokol@um.si)

\section{REFERENCES}

1. Harvey HB, Weinstein DF.. Predatory publishing: an emerging threat to the medical literature. Acad. Med. J. Assoc. Am. Med. Coll. 2017;92:150-1.

2. Shamseer L, Moher D, Maduekwe O, et al. Potential predatory and legitimate biomedical journals: can you tell the difference? A crosssectional comparison. BMC Med. 2017;15:28.

3. List of Predatory Journals I Stop Predatory Journals. Available from https:// predatoryjournals.com/journals/. Last accessed on 15th November 2017.

4. BHI. Predatory Journals - ىجعل و نـــــامعتبر مجلات Available from http://blacklist.research.ac.ir/. Last accessed on 15th November 2017. 